\title{
New challenges for services quality evaluation
}

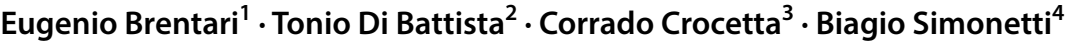

Published online: 14 May 2019

(c) Springer Nature B.V. 2019

This special issue which includes a selection of papers presented at the 8th Scientific Conference: INNOVATION END SOCIETY - Statistical Methods for Evaluation (IES 2017) hosted by the University of Naples Federico II in September 6-7, 2017 and co-organized by the University of Sannio, the University Unitelma-Sapienza, the University L'Orientale di Napoli and the SIS Association.

The primary aim of the meeting was to bring together scientists from different fields, interested to study the impact of innovation and evaluation.

This special issue contains 18 papers, written by authors coming from different countries and offers an overview of statistical approaches and methodologies.

We hope that this volume can became a valuable resource for future researchers and decision makers.

Publisher's Note Springer Nature remains neutral with regard to jurisdictional claims in published maps and institutional affiliations.

Biagio Simonetti

simonetti@unisannio.it

Eugenio Brentari

eugenio.brentari@unibs.it

Tonio Di Battista

dibattis@unich.it

Corrado Crocetta

corrado.crocetta@unifg.it

1 University of Brescia, Brescia, Italy

2 University of Chieti-Pescara, Chieti, Italy

3 University of Foggia, Foggia, Italy

4 University of Sannio, Benevento, Italy 